\title{
Consumption of $100 \%$ Fruit Juice is Associated with Better Nutrient Intake and Diet Quality but not with Weight Status in Children: NHANES 2007-2010
}

\author{
Theresa A. Nicklas ${ }^{1, *}$, Carol E. O’Neil ${ }^{2}$ and Victor L. Fulgoni III ${ }^{3}$ \\ ${ }^{1}$ Department of Pediatrics, Baylor College of Medicine, USDA/ARS Children's Nutrition Research Center, \\ 1100 Bates Street, Houston, TX 77030, USA \\ ${ }^{2}$ School of Nutrition and Food Sciences, Louisiana State University Agricultural Center, 261 Knapp Hall, 110 \\ LSU Union Square, Baton Rouge, LA 70803-0106, USA
}

${ }^{3}$ Nutrition Impact, LLC, 9725 D Drive N, Battle Creek, MI 49014, USA

\begin{abstract}
Objective: This study examined the impact of various levels of $100 \%$ fruit juice (FJ) consumption on intake of nutrients, diet quality, and weight in children using the more recent national data.

Methods: This was a cross-sectional study examining the data from children 2-18 years of age $(n=6,090)$. Intake of nutrients and diet quality were assessed using the 24-hr dietary recall and Healthy Eating Index-2010, respectively. Various consumption levels of $100 \%$ FJ were determined. Covariate adjusted linear regression means, and standard errors were determined $(p<0.01)$.

Results: Average per capita consumption of $100 \%$ FJ consumed was $3.6 \mathrm{fl} \mathrm{oz} \mathrm{(50} \mathrm{kilocalories;} 2.9 \%$ energy intake); $30 \%$ of children 2-6 years exceeded the recommendation for 100\% FJ. Among 100\% FJ consumers, the mean amount of $100 \%$ FJ consumed was $10.6 \mathrm{fl} \mathrm{oz} \mathrm{(147} \mathrm{kilocalories;} 8.4 \%$ energy intake). Intakes of vitamin C, magnesium, and potassium and overall diet quality were higher with more $100 \% \mathrm{FJ}$ consumed; no difference was found in total fiber intake. No trends were seen in weight with increased amounts of $100 \%$ FJ consumed.
\end{abstract}

Conclusions: Consumption of $100 \%$ FJ should be recommended as a component of a healthy diet.

Keywords: Fruit juice, whole fruit, dietary intake, NHANES, children.

\section{INTRODUCTION}

Consumption of fruit has been associated with a variety of health benefits including an improved profile of cardiovascular risk factors (CVRF) [1-5], a reduced risk of hypertension [3], and some types of cancer [1, 6]. The majority of the studies conducted with children have examined the association between $100 \%$ fruit juice (FJ) and weight. Although some studies have shown an association between $100 \%$ FJ consumption and overweight/obesity [7-10], the majority have not supported this relationship [11-18]. A 2008 systematic review showed no consistent association between consumption of $100 \% \mathrm{FJ}$ and overweight/obesity in children and adolescents [19]. In addition to the ongoing debate over the tenuous relationship between $100 \% \mathrm{FJ}$ and weight, there is a concern that $100 \% \mathrm{FJ}$ are sugary drinks that should just be eliminated from the diets of children [20]. This concern over the tenuous adverse relationship with weight and the total sugar content of $100 \%$ FJ has overshadowed the contribution of $100 \%$ FJ to nutrient intake and diet

*Address correspondence to this author at the Department of Pediatrics, Baylor College of Medicine, USDA/ARS Children's Nutrition Research Center, 1100 Bates Street, Houston, TX 77030, USA; Tel: 713-798-7087;

Fax: 713-798-7130; E-mail: tnicklas@bcm.edu quality. The authors of a 2015 systematic review concluded that the "preponderance of evidence supports the position that $100 \%$ fruit juice delivers essential nutrients and phytonutrients, provides yearround access to a variety of fruits, and is a costeffective way to help people meet fruit recommendations" [21].

Few children consume the recommended amounts of fruit per day based on gender, age and activity levels [22]. A substantial part of the total fruit intakes of children is comprised of $100 \% \mathrm{FJ}$ and it is a contributor to their total nutrient intake and overall diet quality [12, 13, 18, 23, 24]. Compared with non-consumers, the overall nutritional profile of those consuming $100 \%$ juice had significantly higher intakes of energy, and energy adjusted intakes of vitamins $C$ and $B_{6}$, potassium, riboflavin, magnesium, iron, and folate and significantly lower intakes of saturated fatty acids, discretionary fat, and added sugars [12, 13, 18, 23, 24]. Consumption of $100 \%$ FJ also contributed to improved diet quality, and was specifically associated with higher intake of whole fruit $[12,18,23]$. Data from the National Health and Nutrition Examination Survey (NHANES) showed that the percentage of children 2-18 years of age (yrs) consuming 100\% FJ has decreased from 
$55 \%$ (2003-2006 NHANES) [24] to $34 \%(2007-2010$ NHANES) reported in this study.

Mean daily juice consumption among children 2-11 yrs was 4.1 fluid ounces ( $\mathrm{fl} \mathrm{oz}$ ) ( 0.5 cup eq) which contributed a mean intake of 58 kilocalories (kcals) (3.3\% of total energy intake) [12]. On average, children consumed less than the maximum amounts of $100 \%$ FJ recommended by the American Academy of Pediatrics (AAP) [25] which is 4 to $6 \mathrm{fl}$ oz per day for children 1-6 yrs and 8 to $12 \mathrm{fl}$ oz per day for children 7 $18 \mathrm{yrs}$.

The 2010 Dietary Guidelines Advisory Committee (DGAC) recognized dietary fiber, calcium, vitamin D, and potassium as nutrients of public health concern. Vitamins $A, C, D$, and magnesium were also identified as nutrients that were under-consumed by certain segments of the population [26]. In previous research $[12,18,23,24]$, consumption of $100 \%$ FJ was associated with higher intakes of many of these shortfall nutrients.

To date, majority of the studies looking at the contribution of $100 \%$ FJ to nutrient intake, diet quality, and weight in children used older NHANES data from 1999-2006 and focused on consumer versus nonconsumers of FJ. The goal of this study was to examine the impact of various levels of $100 \% \mathrm{FJ}$ consumption on intake of nutrients, diet quality, and weight in children 2-18 yrs using the 2007-2010 NHANES consumption and weight data.

\section{MATERIALS AND METHODS}

\section{Data Collection}

The NHANES is now conducted on a continual basis by the National Center for Health Statistics of the Centers for Disease Control and Prevention. One major objective of NHANES is to examine the relationship between diet, nutrition, and health [27]. Details regarding the survey design, content, operations and procedures are available online [27-29].

\section{Study Population and Dietary Intake}

Participants were children 2-18 yrs $(\mathrm{N}=6,090)$ from the 2007-2010 NHANES. Dietary data were obtained from two 24-hour dietary recalls administered using an automated multiple-pass method [30, 31]. The first dietary recall was obtained via an in-person interview (Day 1) in the Mobile Examination Center (MEC) and the second (Day 2) was obtained 3-7 days later via telephone. Parents/guardians provided the 24-hour dietary recalls of children 2-5 yrs; children 6-11 yrs were assisted by an adult; all others provided their own recalls. The following were excluded from the analyses: those with unreliable recall data as assessed by the United States Department of Agriculture (USDA) Food Surveys Research Group $(n=83)$ and those consuming breast milk $(n=5)$. Detailed descriptions of the dietary interview methods are provided in the NHANES MEC In-Person Dietary Interviewers Procedures Manual [32] and in the Phone Follow-up Dietary Interviewer Procedures Manual [33], which includes pictures of the Computer-Assisted Dietary Interview system screens, measurement guides, and charts used to collect dietary information. The NHANES has stringent protocols and procedures that ensure confidentiality and protect individual participants from identification using federal laws [34]. This study was a secondary data analysis which lacked personal identifiers; therefore, this study did not require Institutional Review Board review.

\section{Determination of Intake of $100 \%$ Fruit Juice (FJ), Nutrients and Food Groups}

In this study, $100 \% \mathrm{FJ}$ was defined according to USDA food codes that specifically indicated $100 \%$ FJ (food codes beginning with 612, 641, 6720 and 6721) while juice cocktails, juice punches, juice drinks, or juice beverages were not considered as fruit juice in this study, although they contain some juice [35]. The USDA Food and Nutrient Database for Dietary Studies (FNDDS) v. 4.1 [36] was used to determine the nutrient content of foods in 2007-2008 NHANES survey foods, and the FNDDS v. 5.0 [37] was used to determine the nutrient content of foods contained in 2009-2010 NHANES survey foods. The Food Patterns Equivalent Databases (for 2007-2008 and 2009-2010) were used to assess food group intakes [38, 39]. Using the first dietary recall, children aged 2-18 yrs were identified and separated into four $100 \%$ FJ consumption groups ( $>0 \leq 4 \mathrm{fl} \mathrm{oz},>4 \leq 8 \mathrm{fl} \mathrm{oz},>8 \leq 12 \mathrm{fl} \mathrm{oz}$, and $>12 \mathrm{fl} \mathrm{oz}$ ) or non-consumers.

\section{Diet Quality as Determined by the Healthy Eating Index (HEl-2010)}

The HEl-2010 (HEI) was used to determine diet quality [40]. The SAS code used to calculate HEI-2010 scores using data from the first dietary recall was downloaded from the Center for Nutrition Policy and Promotion website [41]. Briefly, HEI-2010 was designed to evaluate all of the major food groups and major subgroups and nutrients to manage in the diet. 
The twelve HEI-2010 components were summed for a maximum score of 100 points. Components 10 (sodium), 11 (refined grains), and 12 (empty calories) are reverse scored, so that lower intake leads to a higher score, and thus a greater contribution to diet quality.

\section{Anthropometric Measures}

Height and weight were obtained according to NHANES Anthropometry Procedures Manual [42]. The manual provides information about equipment, calibration, methods, quality control, and survey procedures. Body mass index (BMI) was calculated as body weight (in kilograms) divided by height (in meters) squared [43]. The Centers for Disease Control and Prevention's growth chart programs were used to determine BMI z-score; children with a BMI z-score greater than or equal to the 85th and less than 95th, and greater than or equal to the 95th percentile were considered overweight or obese, respectively [44]. Waist circumference (WC) was obtained using NHANES protocol [42].

\section{Statistical Analyses}

Demographics of consumers and non-consumers were determined and compared using t-tests. Regression analyses were used to generate leastsquare means of nutrient intakes, HEl-2010 total score and subcomponents, food group intakes, and anthropometric measures for each 100\% FJ intake group. Logistic regression was utilized to assess the odds ratios of being overweight, obese or overweight/obese for each $100 \%$ FJ intake group. Covariates for these regression analyses were age, gender, race/ethnicity, poverty income ratio grouped into three categories $(<1.25,1.25-3.49$, and $>3.49)$ [45], physical activity (sedentary, moderate and vigorous) [46], current smoking status, alcohol consumption (which was obtained from the 24-hour dietary recall) and total energy intake (the latter was not included in the analysis of energy intake, the HEI-2010 scores, and body weight related parameters). For all regression analyses a $\mathrm{p}$-for-trend-analyses was conducted across levels of $100 \%$ FJ consumption. The National Cancer Institute (NCl) Method was used to estimate usual intake (UI) of $100 \%$ FJ [47]. The two days of intake, using first day sampling weights, were used to obtain necessary variance estimates. The $\mathrm{NCl}$ SAS (SAS Institute, Inc., Cary, NC) macros Mixtran v.1.1 and Distrib v.1.1 were used to generate parameter estimates after covariate adjustment and to estimate the distribution of UI via the Monte Carlo method [48], respectively. The two part correlated model was used for the UI estimations. Covariates used in the $\mathrm{NCI} \mathrm{Ul}$ estimations were day of the week of the 24-hour recall (coded as weekend [Friday-Sunday] or weekday [Monday-Thursday]) and sequence of dietary recall (first or second). The percentage of children with $\mathrm{UI}$ of $100 \%$ FJ exceeding the AAP recommendations for children ages 2-6 yrs and 7-18 yrs was assessed [25]. For all analyses study-specific four-year sample weights [49] were used to adjust the variance for the complex sample design of NHANES using the statistical package SUDAAN (version 9.0.3, 2007, Research Triangle Institute, Research Triangle Park, NC). Significance was set at $p<0.01$.

\section{RESULTS}

\section{Description of Sample}

There was a significantly lower percentage of whites $(p<0.01)$ and older children in the $100 \%$ FJ consumer group; whereas, a smaller percentage of $100 \% \mathrm{FJ}$ consumers reported smoking (Table 1). Of the sample $(n=6,090)$ of $2-18 \mathrm{yrs}, 66 \%$ did not consume $100 \%$ FJ on the day of the recall (Table 2). For the entire population, the mean amount of $100 \%$ FJ consumed daily was $3.6 \mathrm{fl} \mathrm{oz}$, contributing a mean intake of 50 kcals or $2.9 \%$ of total energy intake. Among $100 \%$ FJ consumers only, the mean amount of $100 \%$ FJ consumed daily was $10.6 \mathrm{fl} \mathrm{oz}$, which contributed a mean of $147 \mathrm{kcals}$ or $8.4 \%$ of total energy intake. The mean amount of $100 \%$ FJ consumed was $9.9 \mathrm{fl}$ oz for ages 2-8 yrs and $11.2 \mathrm{fl} \mathrm{oz}$ for 9-18 yrs.

\section{Average Nutrient Intake by $100 \%$ FJ Consumption}

Compared to children who did not consume $100 \%$ FJ, there was a significant $(p<0.0001)$ positive trend with increased amount of $100 \%$ FJ consumed for adjusted total energy intake $(+18.0 \mathrm{kcal} / \mathrm{fl} \mathrm{oz} \mathrm{FJ})$, carbohydrates $(+1.4 \mathrm{~g} / \mathrm{fl} \mathrm{oz} \mathrm{FJ})$, total sugars $(+1.5 \mathrm{~g} / \mathrm{fl}$ oz FJ), vitamin C $(+7.6 \mathrm{mg} / \mathrm{fl} \mathrm{oz} \mathrm{FJ),} \mathrm{magnesium}(+1.3$ $\mathrm{mg} / \mathrm{fl} \mathrm{oz} \mathrm{FJ),} \mathrm{and} \mathrm{potassium} \mathrm{(+30.5} \mathrm{mg/fl} \mathrm{oz} \mathrm{FJ)} \mathrm{(Table}$ $3)$. In contrast, there was a significant $(p<0.001)$ inverse trend for total fat $(-0.5 \mathrm{~g} / \mathrm{fl} \mathrm{oz} F \mathrm{FJ})$, saturated fatty acids (-0.2 g/fl oz FJ), and sodium $(-14.8 \mathrm{mg} / \mathrm{fl} \mathrm{oz}$ FJ) with increased amount of $100 \%$ FJ consumed (Table 3).

\section{Diet Quality and $100 \%$ FJ Consumption}

Compared to non-consumers, diet quality significantly $(p<0.0001) \quad$ increased with increased 
Table 1: Demographics of Children 2-18 Years $(n=6,090)$ Participating in 2007-2010 National Health and Nutrition Examination Survey

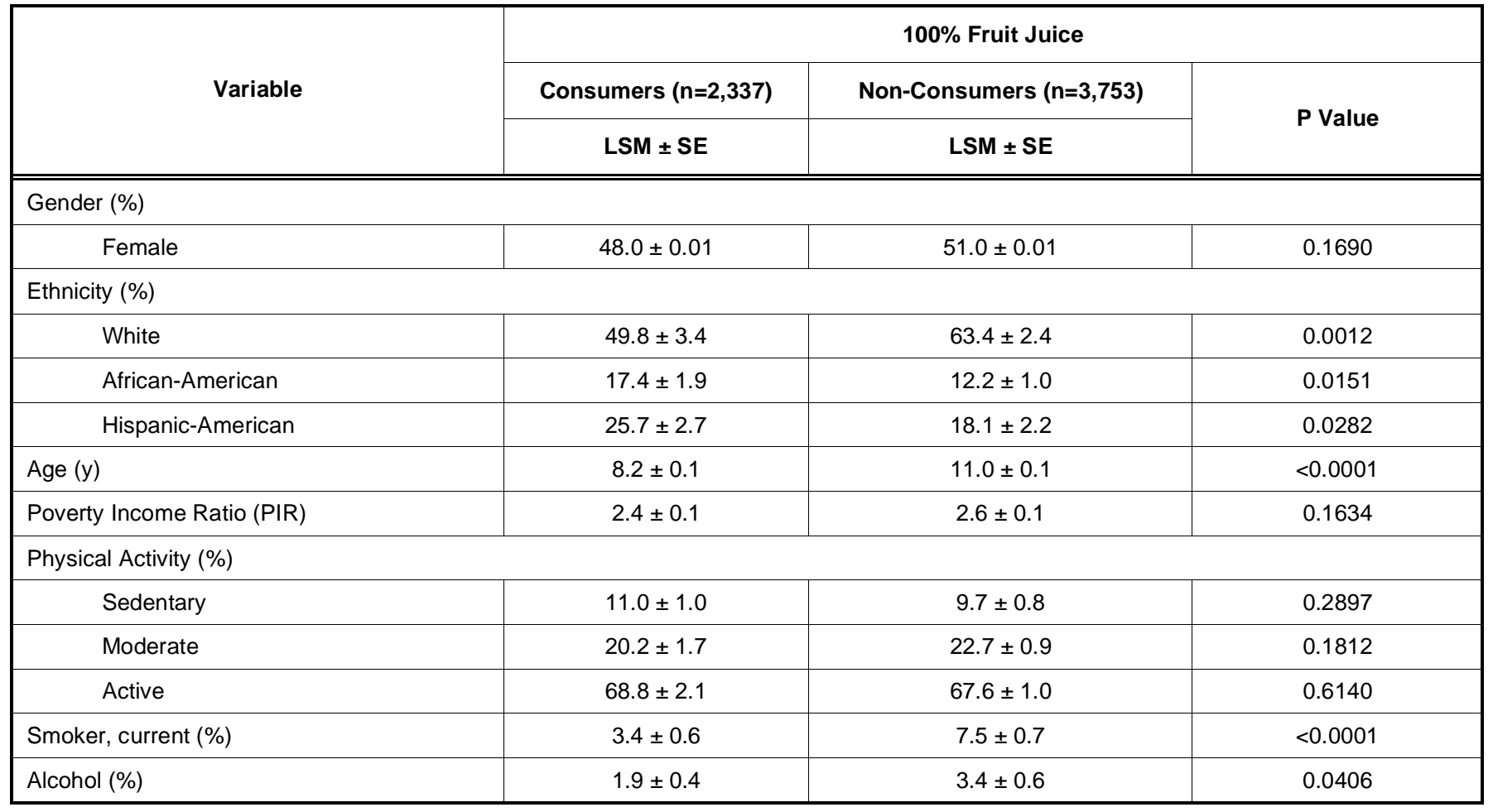

Table 2: $100 \%$ Fruit Juice Consumption Children by Age Group

\begin{tabular}{|c|c|c|c|}
\hline & \multicolumn{2}{|c|}{ Age Group (yrs) } & \multirow{2}{*}{$\begin{array}{c}\text { Total (yrs) } \\
2-18 \\
\bar{x} \pm \text { SE }\end{array}$} \\
\hline & $\begin{array}{c}2-8 \\
X \pm S E\end{array}$ & $\begin{array}{c}9-18 \\
X \pm S E\end{array}$ & \\
\hline Total Population (n) & 2838 & 3252 & 6090 \\
\hline Mean Amount Consumed (fluid ounces) & $4.7 \pm 0.2$ & $2.8 \pm 0.1$ & $3.6 \pm 0.1$ \\
\hline$\%$ of Daily Calories from Juice & $4.1 \pm 0.1$ & $2.0 \pm 0.1$ & $2.9 \pm 0.1$ \\
\hline Non-Juice Consumers (\%) & $52.4 \pm 1.9$ & $75.6 \pm 1.2$ & $66.1 \pm 1.4$ \\
\hline Juice Consumers (\%) & $47.6 \pm 1.9$ & $24.4 \pm 1.2$ & $34.0 \pm 1.4$ \\
\hline \multicolumn{4}{|l|}{$100 \%$ Fruit Juice Consumers Only } \\
\hline
\end{tabular}

amounts of $100 \%$ FJ consumed $(0.4 \mathrm{HEI}-2010$ points/fl oz FJ) (Figure 1). There was a significant $(p<0.0001)$ decrease in intake of solid fat $(-0.4 \mathrm{~g} / \mathrm{fl} \mathrm{Oz} F \mathrm{FJ})$ and added sugars $(-0.3 \mathrm{tsp} / \mathrm{fl}$ oz FJ) with increased amounts of $100 \%$ FJ consumed; $100 \%$ FJ did not appear to displace milk consumption (Figure 2). However, $100 \%$ FJ consumers consumed significantly $(p<0.01)$ more whole fruit than non-consumers $(0.76 \pm$ 0.04 vs. $0.65 \pm 0.04$ cup equivalents) (data not shown).

\section{Percentage of Children Exceeding the AAP Recommendations for $100 \%$ FJ Consumption}

Thirty-two percent of children ages 2-6 yrs consumed more than $6 \mathrm{fl} \mathrm{oz}$ of $100 \% \mathrm{FJ}$, being higher 
Table 3: Adjusted Nutrient Intake by $100 \%$ Fruit Juice Consumption Groups

\begin{tabular}{|c|c|c|c|c|c|c|c|}
\hline \multirow[t]{2}{*}{ Nutrients Per Day ${ }^{1}$} & \multicolumn{5}{|c|}{$\begin{array}{l}100 \% \text { Fruit Juice Consumption Groups (fl oz/Day) } \\
\qquad \text { LSM } \pm \text { SE }\end{array}$} & \multirow[b]{2}{*}{ Beta } & \multirow[b]{2}{*}{ P Trend } \\
\hline & $0 \mathrm{fl} \mathrm{oz}$ & $>0 \leq 4 \mathrm{fl} \mathrm{oz}$ & $>4 \leq 8 \mathrm{fl} \mathrm{oz}$ & $>8 \leq 12 \mathrm{fl} \mathrm{oz}$ & $>$ than $12 \mathrm{fl} \mathrm{oz}$ & & \\
\hline Carbohydrates (g) & $252.6 \pm 1.4$ & $246.9 \pm 7.6$ & $255.7 \pm 2.6$ & $266.4 \pm 2.4$ & $277.0 \pm 3.1$ & 1.43 & $<0.0001$ \\
\hline Total Sugar (g) & $124.0 \pm 1.5$ & $116.3 \pm 8.0$ & $128.3 \pm 2.8$ & $133.0 \pm 2.0$ & $151.2 \pm 3.4$ & 1.48 & $<0.0001$ \\
\hline Total Fat (g) & $71.1 \pm 0.6$ & $71.6 \pm 2.2$ & $69.7 \pm 1.0$ & $66.7 \pm 0.9$ & $62.7 \pm 1.1$ & -0.49 & $<0.0001$ \\
\hline Saturated Fatty Acids (g) & $25.1 \pm 0.2$ & $24.8 \pm 1.5$ & $24.3 \pm 0.5$ & $23.5 \pm 0.5$ & $21.5 \pm 0.4$ & -0.21 & $<0.0001$ \\
\hline Vitamin C (mg) & $56.1 \pm 1.7$ & $75.5 \pm 5.3$ & $95.6 \pm 3.6$ & $119.3 \pm 2.6$ & $209.1 \pm 5.8$ & 7.59 & $<0.0001$ \\
\hline Vitamin $\mathrm{B}_{6}(\mathrm{mg})$ & $1.7 \pm 0.0$ & $1.7 \pm 0.1$ & $1.7 \pm 0.0$ & $1.7 \pm 0.1$ & $1.8 \pm 0.1$ & 0.01 & 0.0027 \\
\hline Calcium (mg) & $994.0 \pm 12.3$ & $1025.3 \pm 68.3$ & $1059.5 \pm 23.6$ & $1069.3 \pm 22.2$ & $1142.6 \pm 37.4$ & 10.10 & 0.0170 \\
\hline Iron (mg) & $13.6 \pm 0.2$ & $14.6 \pm 0.6$ & $13.5 \pm 0.2$ & $13.7 \pm 0.4$ & $13.5 \pm 0.4$ & 0.00 & 0.9755 \\
\hline Sodium (mg) & $3091.8 \pm 30.2$ & $3135.3 \pm 100.4$ & $3036.1 \pm 49.3$ & $2955.4 \pm 40.4$ & $2814.4 \pm 54.1$ & -14.76 & 0.0003 \\
\hline Potassium (mg) & $2067.0 \pm 25.2$ & $2139.8 \pm 67.0$ & $2239.6 \pm 25.6$ & $2306.7 \pm 30.0$ & $2677.3 \pm 60.6$ & 30.49 & $<0.0001$ \\
\hline
\end{tabular}

${ }^{1}$ Adjusted for gender, race/ethnicity, age, and energy intake.

${ }^{2}$ Adjusted for gender, race/ethnicity, and age.

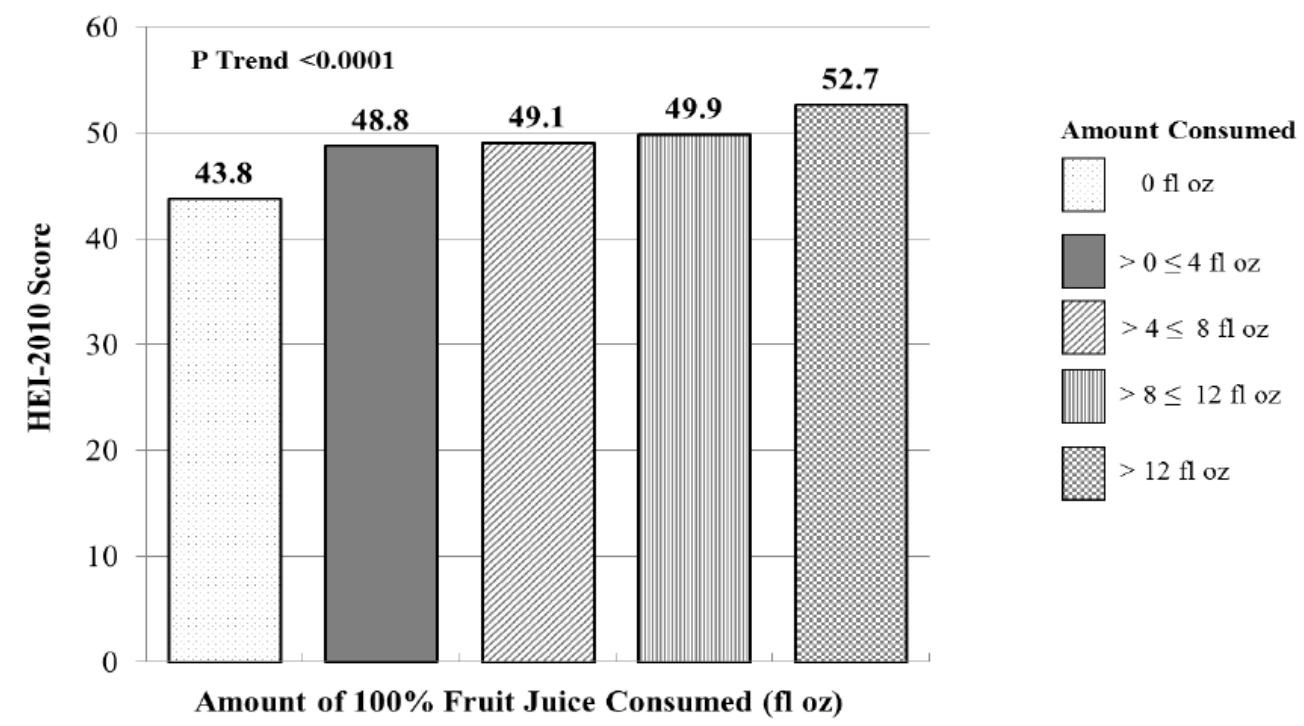

Figure 1: Diet quality by $100 \%$ fruit juice consumption.

among males (35\%) than females (29\%). Only $2 \%$ of children $7-18$ yrs consumed more than $12 \mathrm{fl} \mathrm{oz}$ of $100 \%$ FJ (Figure 3).

\section{Mean Levels of Adiposity Measured by $100 \%$ FJ Consumption}

No significant trends were found in BMI, BMI Zscores, and WC with increased amount of $100 \% \mathrm{FJ}$ consumed (Table 4). There were no differences in the likelihood of being overweight or obese among the $100 \%$ FJ consumption groups compared to nonconsumers (Figure 4).

\section{DISCUSSION}

On average, the entire population of children 2-18 yrs consumed only $3.6 \mathrm{fl} \mathrm{oz}$ of $100 \% \mathrm{FJ}$; in consumers 


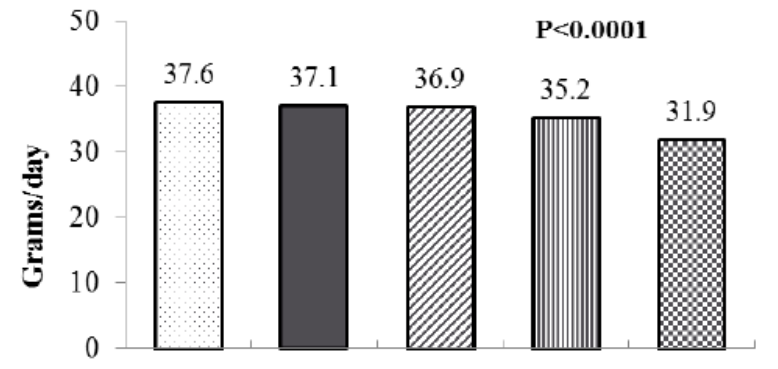

Solid Fat

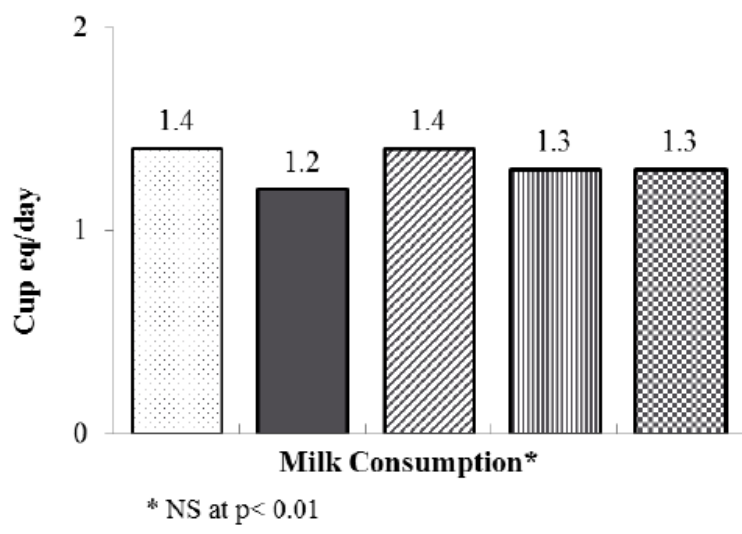

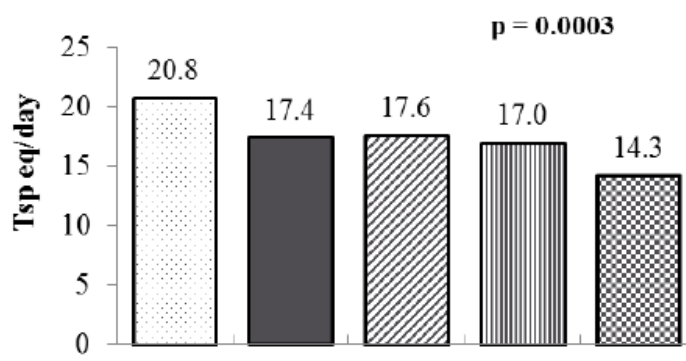

Added Sugars

\section{Amount Consumed}

$0 \mathrm{fl} \mathrm{oz}$

$>0 \leq 4 \mathrm{fl} \mathrm{oz}$

$>4<8 \mathrm{fl} \mathrm{oz}$

$>8 \leq 12 \mathrm{fl} \mathrm{oz}$

$>12 \mathrm{fl} \mathrm{oz}$

Figure 2: Intakes of solid fat, added sugars, and milk by $100 \%$ fruit juice consumption.
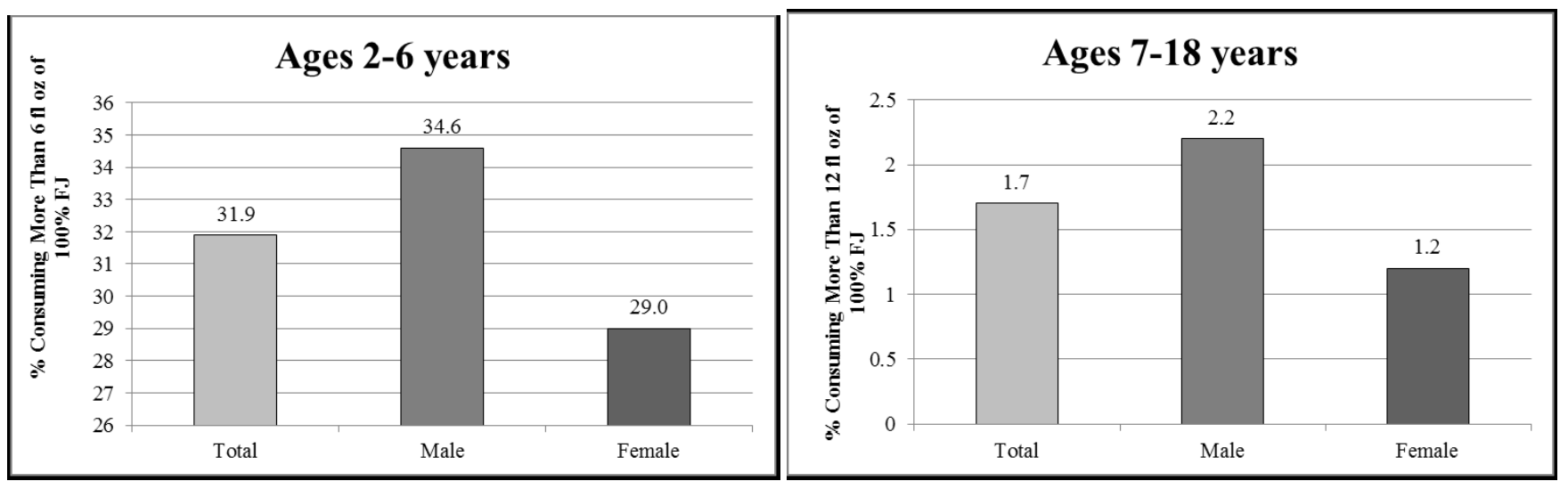

Figure 3: Percentage of children exceeding the American academy of pediatrics recommendations for $100 \%$ fruit juice consumption.

Table 4: Adjusted Obesity Measures for 100\% Fruit Juice Consumers

\begin{tabular}{|c|c|c|c|c|c|c|}
\hline Adiposity Measures & \multicolumn{5}{|c|}{$\begin{array}{l}\text { 100\% Fruit Juice Consumption Groups }{ }^{1} \\
\text { (LSM } \pm \text { SE) }\end{array}$} & P Trend \\
\hline Body Mass Index, $\mathrm{kg} / \mathrm{m}^{2}$ & $20.1 \pm 0.13$ & $19.7 \pm 0.25$ & $19.8 \pm 0.25$ & $19.7 \pm 0.26$ & $20.3 \pm 0.23$ & 0.6364 \\
\hline BMI z-Score & $0.49 \pm 0.04$ & $0.26 \pm 0.08$ & $0.42 \pm 0.07$ & $0.39 \pm 0.07$ & $0.49 \pm 0.06$ & 0.6126 \\
\hline
\end{tabular}

${ }^{1}$ Consumers vs. Non-Consumers: BMI, WC, and BMI z-score were not significantly different.

${ }^{2}$ Adjusted for gender, race/ethnicity, age, and energy intake.

${ }^{3}$ Calculated as weight in kilograms divided by height in meters squared. 

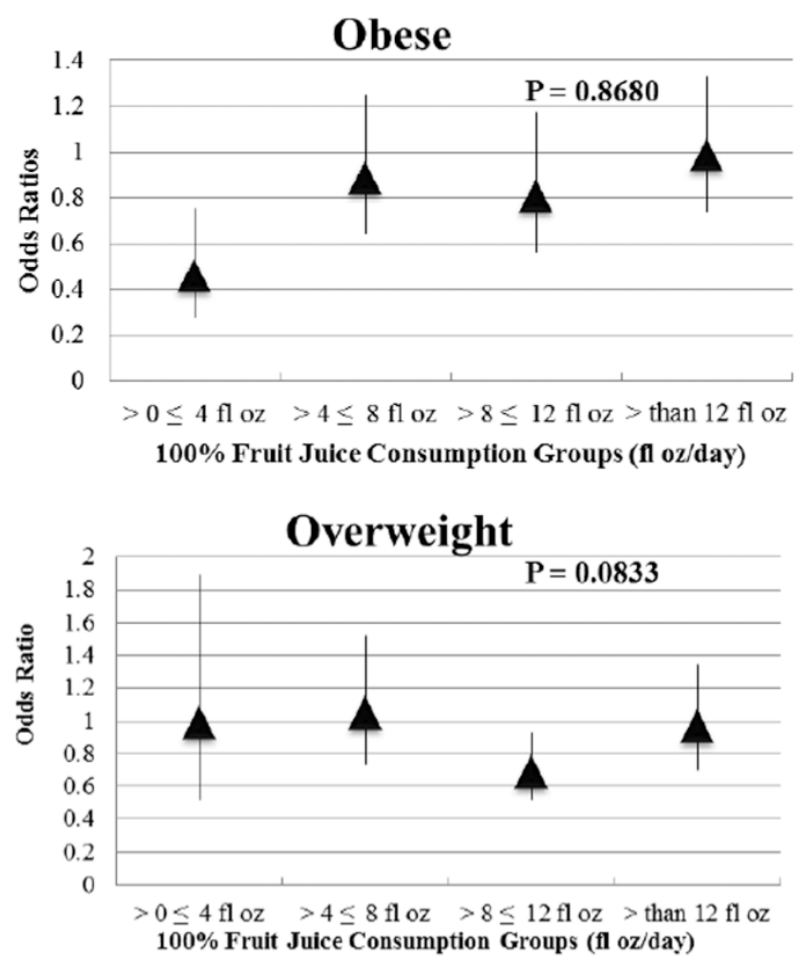

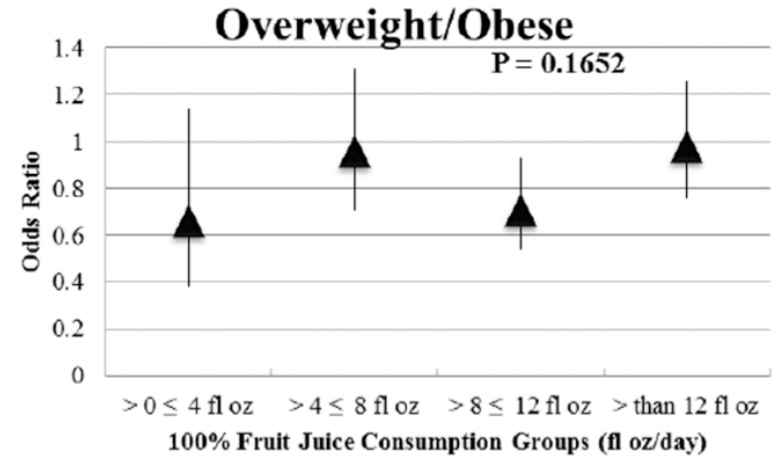

$100 \%$ Fruit Juice Consumption Groups (fl oz/day)

Figure 4: Likelihood of being overweight and/or obese by $100 \%$ fruit juice consumption.

Consumers only: the odds of being overweight and/or obese was not significant at $p<0.01$.

FJ consumption was $10.6 \mathrm{fl} \mathrm{oz/d}$. The 2010 DGA [50] did not make a specific recommendation for $100 \% \mathrm{FJ}$ consumption with the exception that the majority of fruit consumed should be whole fruit. Among those children drinking $100 \% \mathrm{FJ}$, mean intake was higher in the younger age group. Approximately one-third of children 2-6 yrs exceeded the AAP recommendations of 4-6 fl oz per day. Thus, intakes above recommendations should be monitored by practitioners to ensure that intakes are not excessive for calories recommended.

The percentage of $100 \%$ FJ consumption was age dependent; younger children had a significantly higher percentage of consumers than older children. This is consistent with other findings [12, 23, 24]. Despite the age difference in the prevalence of $100 \% \mathrm{FJ}$ consumption, mean intakes did not exceed AAP recommendations [25]. Overall, the mean energy intake of children consuming the highest amounts of $100 \%$ FJ was higher than children consuming no $100 \%$ FJ. This is consistent with one study that found that with increased intake of any type of beverage [14], including $100 \% \mathrm{FJ}$, total energy intake increased, though BMI did not increase. Although higher intakes of $100 \%$ FJ were not associated with increased weight, more longitudinal studies are needed to understand the effect of increased energy intake associated with increased $100 \%$ FJ consumption on weight.
Children consuming 100\% FJ had better nutrient intake, especially potassium-a nutrient of public health concern, and diet quality compared to nonconsumers. Mean intakes of vitamin C, magnesium, and potassium increased with increased amounts of $100 \%$ FJ consumed. There was no difference in total fiber intake between 100\% FJ consumers and nonconsumers and there was no significant impact on fiber intake as FJ increased. Moreover, mean intake of total fat, saturated fatty acid, and sodium decreased with increased amounts of $100 \%$ FJ consumed.

There is a concern that $100 \%$ FJ are "sugary drinks" that should be eliminated from the diet [45]. This concern was ignited with the comparison of the total sugar content of $100 \%$ FJ with sugar sweetened beverages. Twelve $\mathrm{fl}$ oz of a typical sugar-sweetened beverage contains 8 tsp eq ( 40 g) sugar and 152 kcals compared to 6 tsp eq ( $\sim 31 \mathrm{~g})$ sugar and 167 kcals in $12 \mathrm{fl} \mathrm{oz}$ of orange juice [51]. Data from this study showed that mean intake of total sugars increased with increased amounts of $100 \%$ FJ consumed. However, the total sugar content in a typical sugar-sweetened beverage is added sugars and 100\% FJ by definition contains no added sugars. This explains, at least in part, why consumers of $100 \% \mathrm{FJ}$, in this study, had lower intakes of added sugars despite the increased intakes of total sugars. 
In addition to better nutrient intake, consumers of $100 \%$ FJ also had better diet quality than nonconsumers; lower intakes of solid fats and added sugars and higher intakes of whole fruit $[12,23]$. Thus, the concern over the total sugar content of $100 \% \mathrm{FJ}$ has overshadowed the contribution of $100 \% \mathrm{FJ}$ to nutrient intake and diet quality. Another concern about consumption of $100 \% \mathrm{FJ}$ is that it may displace fluids like milk in the diet. Data from this study and another study [12] showed that $100 \%$ FJ did not replace milk in the diets of children. And finally, consumers of $100 \%$ FJ had improved intake of whole fruit. Thus, consumption of $100 \%$ FJ may be one way to increase fruit intake and should be encouraged as part of a healthy diet when consumed in age appropriate amounts [25].

The rationale for the AAP recommendations for $100 \%$ FJ consumption in children is not completely clear; however it is, in part, based on one study that showed an association of $100 \%$ FJ consumption and overweight in pre-school aged children [7]. Since that study was published, the association between overweight/obesity in children and consumption of $100 \%$ FJ appear unfounded [19]. Data from this study demonstrates that $100 \%$ FJ consumption was not associated with weight status of children. The verdict is not established until causality can be shown in studies with a more rigorous research design.

\section{LIMITATIONS}

This study had a number of limitations. NHANES is a cross-sectional study, thus cause and effect relationships cannot be determined. Another noteworthy limitation is the use of dietary recalls to assess intake in NHANES. Participants relied on memory to self-report dietary intakes; therefore, data were subject to non-sampling errors, including underor over-reporting of energy. Parents reported or assisted their children 2-11 yrs with the 24-hour recalls; parents often report accurately what children eat in the home [52] but may not know what their children consume outside the home [53], which could also result in reporting errors [54]. Specific to $100 \% \mathrm{FJ}$ consumption data, parents and children may not know whether the FJ consumed was $100 \%$ FJ or a blended juice beverage; therefore, data were subject to additional reporting errors. It is important to recognize that the results from this study do not reflect the effect of $100 \%$ FJ consumption specifically, but rather the consumption of $100 \%$ FJ within the context of the total diet. The results could reflect other foods consumed throughout the day among $100 \%$ FJ consumers compared to non-consumers. Practitioners need to monitor $100 \%$ FJ consumption, particularly among younger children, to ensure that intakes are not excessive for calories recommended.

\section{CONCLUSION}

Consumption of $100 \%$ FJ was associated with better nutrient intake and diet quality and was not associated with body weight/adiposity in a nationally representative sample of children. Thus, consumption of $100 \%$ FJ should be recommended as a component of a healthy diet. In conclusion, $100 \%$ FJ is not just another sugary drink that may contribute to adiposity among some children.

\section{CONFLICTS OF INTEREST}

None of the authors have any conflict of interests to report.

\section{ACKNOWLEDGEMENTS}

This work is a publication of the USDA/ARS Children's Nutrition Research Center, Department of Pediatrics, Baylor College of Medicine, Houston, Texas. The contents of this publication do not necessarily reflect the views or policies of the USDA, nor does mention of trade names, commercial products, or organizations imply endorsement from the U.S. government. Partial support was received from the United States Department of Agriculture/ Agricultural Research Service (USDA/ARS) through specific cooperative agreement 58-6250-6-003 and from the USDA Hatch Project LAB 94209. Partial support was also received by the Juice Products Association. T.A.N, C.O'N. and V.L.F contributed to the concept development and the overall research plan; V.L.F. contributed to the methodological and statistical aspects of the work; T.A.N. wrote the initial draft; C.O'N. and V.L.F. reviewed and edited the manuscript and data. All authors read and approved the final manuscript.

\section{REFERENCES}

[1] Global Strategy on Diet, Physical Activity and Health: Diet, nutrition and the prevention of chronic diseases. Report of the joint WHO/FAO expert consultation. WHO Technical Report Series, No. 916 (TRS 916), 2003; [cited 2015 Apr 1]: Available from: http://www.who.int/dietphysicalactivity/en/

[2] Mirmiran P, Noori N, Zavareh MB, Azizi F. Fruit and vegetable consumption and risk factors for cardiovascular disease. Metabolism: Clinical and Experimental 2009; 58: 460-8.

http://dx.doi.org/10.1016/j.metabol.2008.11.002 
[3] He FJ, Nowson CA, Lucas M, MacGregor GA. Increased consumption of fruit and vegetables is related to a reduced risk of coronary heart disease: meta-analysis of cohort studies. J Hum Hypertens 2007; 21: 717-28.

http://dx.doi.org/10.1038/sj.jhh.1002212

[4] Hung HC, Joshipura KJ, Jiang R, et al. Fruit and vegetable intake and risk of major chronic disease. J Natl Cancer Inst 2004; 96: 1577-84.

http://dx.doi.org/10.1093/jnci/djh296

[5] Dauchet L, Amouyel P, Hercberg S, Dallongeville J. Fruit and vegetable consumption and risk of coronary heart disease: a meta-analysis of cohort studies. J Nutr 2006; 136: 2588-93.

[6] Oyebode O, Gordon-Dseagu V, Walker A, Mindell JS. Fruit and vegetable consumption and all-cause, cancer and CVD mortality: analysis of Health Survey for England data. $J$ Epidemiol Community Health 2014; 68: 856-62.

http://dx.doi.org/10.1136/jech-2013-203500

[7] Dennison BA, Rockwell HL, Baker SL. Excess fruit juice consumption by preschool-aged children is associated with short stature and obesity. Pediatrics 1997; 99: 15-22.

[8] Epstein LH, Gordy CC, Raynor HA, Beddome M, Kilanowski CK, Paluch RA. Increasing fruit and vegetable intake and decreasing fat and sugar intake in families at risk for childhood obesity. Obes Res 2001; 9: 171-8.

http://dx.doi.org/10.1038/oby.2001.18

[9] Faith MS, Dennison BA, Edmunds LS, Stratton HH. Fruit juice intake predicts increased adiposity gain in children from low-income families: weight status-by-environment interaction. Pediatrics 2006; 118: 2066-75. http://dx.doi.org/10.1542/peds.2006-1117

[10] Melgar-Quinonez HR, Kaiser LL. Relationship of childfeeding practices to overweight in low-income MexicanAmerican preschool-aged children. J Am Diet Assoc 2004; 104: $1110-9$ http://dx.doi.org/10.1016/j.jada.2004.04.030

[11] Newby PK, Peterson KE, Berkey CS, Leppert J, Willett WC, Colditz GA. Beverage consumption is not associated with changes in weight and body mass index among low-income preschool children in North Dakota. J Am Diet Assoc 2004; 104: 1086-94.

http://dx.doi.org/10.1016/j.jada.2004.04.020

[12] Nicklas TA, O'Neil CE, Kleinman RE. Association between $100 \%$ fruit juice consumption and nutrient intake and weight of children 2 to 11 years. Archive of Pediatric and Adolescent Medicine 2008; 162: 557-67.

http://dx.doi.org/10.1001/archpedi.162.6.557

[13] O'Neil CE, Nicklas TA, Kleinman R. Relationship between $100 \%$ juice consumption and nutrient intake and weight of adolescents. Am J Health Promot 2010; 24: 231-7. http://dx.doi.org/10.4278/ajhp.080603-QUAN-76

[14] O'Connor TM, Yang SJ, Nicklas TA. Beverage intake among preschool children and its effect on weight status. Pediatrics 2006; 118: e1010-8.

http://dx.doi.org/10.1542/peds.2005-2348

[15] La Rowe TL, Moeller SM, Adams AK. Beverage patterns, diet quality, and body mass index of US preschool and schoolaged children. J Am Diet Assoc 2007; 107: 1124-33.

http://dx.doi.org/10.1016/j.jada.2007.04.013

[16] Forshee RA, Storey ML. Total beverage consumption and beverage choices among children and adolescents. Int $\mathrm{J}$ Food Sci Nutr 2003; 54: 297-307. http://dx.doi.org/10.1080/09637480120092143

[17] Academy of Nutrition and Dietetics. Evidence Analysis Library. What is the association between intake of $100 \%$ fruit juice and weight status or adiposity (e.g., BMI percentile, rate of weight gain, BMI z-score, and fat mass) in children? 2014; [cited 2015 Apr 1]: Available from: http://ada.portalxm.com/ eal/conclusion.cfm?conclusion_statement_id $=252194$
[18] O'Neil C, Nicklas T, Rampersaud G, Fulgoni VR. One hundred percent orange juice consumption is associated with better diet quality, improved nutrient adequacy, and no increased risk for overweight/obesity in children. Nutr Res 2011; 31: 673-82.

http://dx.doi.org/10.1016/j.nutres.2011.09.002

[19] O'Neil C, Nicklas T. A Review of the Relationship between $100 \%$ Fruit Juice Consumption and Weight in Children and Adolescents. American Journal of Lifestyle Medicine 2008; 2: 315-54. http://dx.doi.org/10.1177/1559827608317277

[20] Gill J, Sattar N. Fruit juice: just another sugary drink? Lancet Diabetes \& Endocrinology 2014; 2: 444-6. http://dx.doi.org/10.1016/S2213-8587(14)70013-0

[21] Clemens R, Drewnowski A, Ferruzzi MG, Toner CD, Welland D. Squeezing fact from fiction about $100 \%$ fruit juice. Advances in Nutrition 2015; 6: 236S-43S. http://dx.doi.org/10.3945/an.114.007328

[22] National Cancer Institute. Usual Dietary Intakes: Recommended amounts of total fruits table, 2014; [cited $2015 \mathrm{Apr}$ 1]: Available from: http://appliedresearch.cancer. gov/diet/usualintakes/pop/2007-10/table_b01.html

[23] O'Neil C, Nicklas T, Zanovec M, Fulgoni III V. Diet quality is positively associated with $100 \%$ fruit juice consumption in children and adults in the United States: NHANES 20032006. Nutr J 2011; 10: 1-10. http://dx.doi.org/10.1186/1475-2891-10-17

[24] O'Neil CE, Nicklas TA, Zanovec M, Kleinman RE, Fulgoni III VL. Fruit juice consumption is associated with improved nutrient adequacy in children and adolescents: the National Health and Nutrition Examination Survey (NHANES) 20032006. Public Health Nutr 2012; 15: 1871-8. http://dx.doi.org/10.1017/S1368980012000031

[25] American Academy of Pediatrics. Policy Statement: Use and Misuse of Fruit Juice in Pediatrics. Pediatrics 2001. Reaffirmed August 2013; 107: 1210-3.

[26] United States Department of Agriculture. Center for Nutrition Policy and Promotion. Dietary Guideline for Americans, 2010. Report of the Dietary Guidelines Advisory Committee on the Dietary Guidelines for Americans, 2010; [cited 2015 Apr 1]: Available from: http://www.cnpp.usda.gov/dietaryguidelines-2010

[27] Centers for Disease Control and Prevention. National Health and Nutrition Examination Survey (NHANES) 2007-2008. Public Data General Release File Documentation, 2009; [cited 2015 Mar 9]: Available at: http://www.cdc.gov/nchs/ nhanes/nhanes2007-2008/generaldoc_e.htm

[28] United States Department of Health and Human Services. Centers for Disease Control and Prevention. National Center for Health Statistics. National Health and Nutrition Examination Survey (NHANES), 2013-2014. Overview. Let's improve our health, 2013; [cited 2015 Mar 9]: Available at: http://www.cdc.gov/nchs/data/nhanes/nhanes_13_14/201314_overview_brochure.pdf

[29] Centers for Disease Control and Prevention. National Center for Health Statistics. National Health and Nutrition Examination Survey. Questionnaires, Datasets, and Related Documentation, 2014; [cited 2015 Mar 9]: Available from: http://www.cdc.gov/nchs/nhanes/nhanes_questionnaires.htm

[30] Moshfegh AJ, Rhodes DG, Baer DJ, et al. The US Department of Agriculture Automated Multiple-Pass Method reduces bias in the collection of energy intakes. Am J Clin Nutr 2008; 88: 324-32.

[31] Blanton CA, Moshfegh AJ, Baer DJ, Kretsch MJ. The USDA Automated Multiple-Pass Method accurately estimates group total energy and nutrient intake. J Nutr 2006; 136: 2594-9.

[32] National Center for Health Statistics (NHANES). MEC InPerson Dietary Interviewers Procedures Manual, 2002; [cited 
2015 Mar 9]: Available at: http://www.cdc.gov/nchs/data/ nhanes/nhanes_01_02/dietary_year_3.pdf

[33] National Center for Health Statistics. Phone Follow-up Dietary Interviewer Procedures Manual, 2004; [cited 2015 Apr 1]: Available from: http://www.cdc.gov/nchs/data/nhanes/ nhanes_03_04/DIETARY_PFU.pdf

[34] Centers for Disease Control and Prevention. National Health and Nutrition Examination Survey. Is my survey information confidential? 2013; [cited 2015 Apr 1]: Available from: http://www.cdc.gov/nchs/nhanes/participant.htm\#confidentiali ty

[35] United States Department of Health and Human Services. Federal Food and Drug Administration. Part 101 - Food Labeling, Subpart B, Sec. 101.3. Percentage of juice declaration for foods purporting to be beverages that contain fruit or vegetable juice [21CFR101.30], 2014; [cited 2015 Apr 1]: Available from: http://www.accessdata.fda.gov/scripts/ cdrh/cfdocs/cfcfr/CFRSearch.cfm?fr $=101.30$

[36] United States Department of Agriculture. Agricultural Research Service. USDA Food and Nutrient Database for Dietary Studies, 4.0, 2010; [cited 2015 Apr 1]: Available from: http://www.ars.usda.gov/Services/docs.htm?docid=12068

[37] United States Department of Agriculture. Agricultural Research Service. USDA Food and Nutrient Database for Dietary Studies, 5.0, 2012; [cited 2015 Apr 1]: Available from: http://www.ars.usda.gov/Services/docs.htm?docid=12068

[38] United States Department of Agriculture. Agricultural Research Service. Food Patterns Equivalents Database 2007-08: Methodology and User Guide, 2013; [2015 Apr 1]: Available at: http://www.ars.usda.gov/SP2UserFiles/Place/ 12355000/pdf/fped/FPED_0708.pdf

[39] Bowman SA, Clemens JC, Thoerig RC, Friday JE, Shimizu M, Moshfegh AJ. Food Patterns Equivalents Database 200910: Methodology and User Guide [Online].]. : Food Surveys Research Group. Beltsville Human Nutrition Research Center. Agricultural Research Service. U.S. Department of Agriculture, Beltsville, Maryland 2013.

[40] Guenther P, Casavale K, Reedy J, et al. Update of the Healthy Eating Index: HEI-2010. J Acad Nutr Diet 2013; 113: 569-80.

http://dx.doi.org/10.1016/j.jand.2012.12.016

[41] Guenther PM, Kirkpatrick SJ, Reedy J, et al. The Healthy Eating Index-2010 is a valid and reliable measure of diet quality according to the 2010 Dietary Guideines for Americans. J Nutr 2014; 144: 399-407. http://dx.doi.org/10.3945//jn.113.183079

[42] National Center for Health Statistics. The NHANES Anthropometry Procedures Manual, 2007; [cited 2015 Apr 1]: Available from: http://www.cdc.gov/nchs/data/nhanes/ nhanes_07_08/manual_an.pdf
[43] National Cholesterol Education Program. National Heart, Lung, and Blood Institute. National Institutes of Health. Detection, Evaluation, and Treatment of High Blood Cholesterol in Adults (Adult Treatment Panel III) Final Report. Circulation 2002; 106: 3143-421.

[44] Centers for Disease Control and Prevention. Computer programs. Growth charts, 2014; [cited 2015 Apr 1]: Available from: http://www.cdc.gov/growthcharts/computer_programs. $\mathrm{htm}$

[45] National Health and Nutrition Examination Survey. 20032004 Data Documentation, Codebook, and Frequencies. Demographic Variables and Sample Weights (Demo_C), 2009: [cited 2015 Apr 1]: Available from: http://www.cdc.gov/ nchs/nhanes/nhanes2003-2004/DEMO_C.htm

[46] National Center for Health Statistics. NHANES Documentation, Codebook, and Frequencies: Survey years 2003-2004. Physical Activity, 2007; [cited 2015 Apr 1]: Available from: http://wwwn.cdc.gov/nchs/nhanes/20032004/PAXRAW_C.htm

[47] National Cancer Institute. Usual Dietary Intakes: The NCl Method, 2013; [cited 2015 Apr 1]: Available from: http://appliedresearch.cancer.gov/diet/usualintakes/method.h tml

[48] National Cancer Institute. Usual Dietary Intakes: SAS Macros for Analysis of a Single Dietary Component, 2013; [cited 2015 Apr 1]: Available from: http://appliedresearch.cancer. gov/diet/usualintakes/macros_single.html

[49] Centers for Disease Control and Prevention. The National Health and Nutrition Examination Survey. Analytic and Reporting Guidelines, 2011-2012; [cited 2015 Mar 9]: Available from: http://www.cdc.gov/nchs/nhanes/analytic_ guidelines.htm

[50] Office of Disease Prevention and Health Promotion. Dietary Guidelines for Americans, 2010; [cited 2015 Apr 1]: Available from: http://www.health.gov/dietaryguidelines/2010.asp

[51] United States Department of Agriculture. Agricultural Research Service. National Nutrient Database for Standard Reference Release 27. Available from: http://ndb.nal.usda. gov/ndb/foods

[52] Basch CE, Shea S, Arliss R, et al. Validation of mothers' reports of dietary intake by four to seven year- old children. Am J Public Health 1990; 80: 1314-7. http://dx.doi.org/10.2105/AJPH.80.11.1314

[53] Baranowski T, Sprague D, Baranowski JH, Harrison JA. Accuracy of maternal dietary recall for preschool children: socioeconomic status and daycare factors. J Am Diet Assoc 1991; 91: 669-74.

[54] Schoeller DA. How accurate is self-reported dietary energy intake? Nutr Rev 1990; 48: 373-9. http://dx.doi.org/10.1111/j.1753-4887.1990.tb02882.x

(c) 2015 Nicklas et al.; Licensee Lifescience Global.

This is an open access article licensed under the terms of the Creative Commons Attribution Non-Commercial License (http://creativecommons.org/licenses/by-nc/3.0/) which permits unrestricted, non-commercial use, distribution and reproduction in any medium, provided the work is properly cited. 